\title{
Blastema Predominant Kidney Wilms Tumor
}

National Cancer Institute

\section{Source}

National Cancer Institute. Blastema Predominant Kidney Wilms Tumor. NCI Thesaurus.

Code C9147.

Wilms tumor of the kidney characterized by the predominance of the blastema

component. 